\title{
THE G-DRAZIN INVERSES OF SPECIAL OPERATOR MATRICES
}

\author{
HuANYIN CHEN AND MARJAN SHEIBANI*
}

Abstract. An element $a$ in a Banach algebra $\mathscr{A}$ has g-Drazin inverse provided that there exists $b \in \mathscr{A}$ such that $b=b a b, a b=b a, a-a^{2} b \in \mathscr{A}^{\text {qnil }}$. In this paper we give a computational formula for the g-Drazin inverse of operator matrix $\left(\begin{array}{ll}E & I \\ F & 0\end{array}\right)$ which was posed by Campbell in the research on singular differential equations.

Mathematics subject classification (2010): 15A09, 47A11, 47A53.

Keywords and phrases: g-Drazin inverse, operator matrix, Banach algebra.

\section{REFERENCES}

[1] C. BU, K. Zhang AND J. ZhaO, Representation of the Drazin inverse on solution of a class singular differential equations, Linear \& Multilinear Algebra 59 (2011), 863-877.

[2] S. L. CAMPBELL, The Drazin inverse and systems of second order linear differential equations, Linear \& Multilinear Algebra 14 (1983), 195-198.

[3] N. Castro-González and E. Dopazo, Representations of the Drazin inverse for a class of block matrices, Linear Algebra Appl. 400 (2005), 253-269.

[4] N. C. González And J. J. Koliha, New additive results for the g-Drazin inverse, Proc. Roy. Soc. Edinburg, Sect. A, 134 (2004), 1085-1097.

[5] D. S. CVetKoviC-Ilic, Some results on the $(2,2,0)$ Drazin inverse problem, Linear Algebra Appl. 438 (2013), 4726-4741.

[6] D. S. Cvetković-ILIĆ, D. S. DjordjeviĆ AND Y. Wei, Additive results for the generalized Drazin inverse in a Banach algebra, Linear Algebra Appl. 418 (2006), 53-61.

[7] Y. Liao, J. Chen and J. Cui, Cline's formula for generalized Drazin inverse, B Malays Math Sci So. 37 (2014), 37-42.

[8] P. Patricio And R. E. Hartwig, The $(2,2,0)$ Drazin inverse problem, Linear Algebra Appl. 437 (2012), 2755-2772.

[9] D. ZHANG, Representations for generalized Drazin inverse of operator matrices over a Banach space, Turk. J. Math. 40 (2016), 428-437.

[10] D. ZHANG AND D. Mosić, Explicit formulae for the generalized Drazin inverse of block matrices over a Banach algebra, Filomat 32 (2018), 5907-5917. 